\title{
Preparation and Characterization of Sustained Release Matrix Tablets of Tizanidine Hydrochloride for Spinal Injuries
}

\author{
Zun-Cheng Zheng ${ }^{\star}$, Xiao-Yu Wang, and Xiao-Jing Du \\ Department of Rehabilitation Medicine, The Central Hospital of Tai'an, Tai'an, 271000, China
}

*For correspondence: Email: zhengzc1967@gmail.com; Tel: 0086-538-6298680; Fax: 0086-538-8223227

Received: 18 April 2015

Revised accepted: 2 September 2015

\begin{abstract}
Purpose: To formulate matrix type sustained-release (SR) tablets of tizanidine hydrochloride (TH) for prolonged drug release and improvement in motor activity after spinal injuries.

Methods: Matrix tablets were prepared by the wet granulation method using four polymers (hydroxyl propyl methyl cellulose [HPMC] K 100, ethyl cellulose [EC], guar gum, and polyvinylpyrrolidone (PVP K30) and characterized for hardness, friability, drug content, swelling, weight variation, in vitro drug release, and in vivo motor function activity using the spinal injury rat model.

Results: All tablets showed good drug content, hardness, and other physicochemical properties. The tablet formulations showed a percent drug release ranging from $92.54 \pm 1.02$ to $98.56 \pm 1.26 \%$ at the end of $12 \mathrm{~h}$. Using the spinal injury rat model, negative control had a motor activity of only $12.75 \%$, while F4 (containing HPMC, EC, and PVP) and F5 (containing EC, guar gum, and PVP) had motor activities of $62.25 \%$ and $57.5 \%$, respectively, compared with $68.0 \%$ for normal controls.

Conclusion: SR matrix tablets of TH showed significant improvement in motor activity in post-traumatic spinal injury rat model.
\end{abstract}

Keywords: Sustained release tablet, Spinal injuries, Matrix tablet, Tizanidine hydrochloride

Tropical Journal of Pharmaceutical Research is indexed by Science Citation Index (SciSearch), Scopus, International Pharmaceutical Abstract, Chemical Abstracts, Embase, Index Copernicus, EBSCO, African Index Medicus, JournalSeek, Journal Citation Reports/Science Edition, Directory of Open Access Journals (DOAJ), African Journal Online, Bioline International, Open-J-Gate and Pharmacy Abstracts

\section{INTRODUCTION}

Oral sustained-release (SR) drug delivery systems are designed to deliver therapeutically effective concentrations of drug to the systemic circulation over an extended period of time. In general, conventional dosage forms are associated with various limitations, such as drug plasma level fluctuations (leading to adverse effects or toxicity due to overdoses), high dosage frequency, high dosage requirements, and poor patient compliance. For effective treatment, the drug plasma concentration must be maintained within a therapeutic range. The SR form decreases side effects and increases patient compliance, due to reduction in frequency of dosing. The SR form also maintains constant blood levels, and avoids drug plasma level fluctuations associated with conventional immediate release formulations [1].

Spinal injury (SI), especially post-traumatic injury, can be devastating to the patient. To repair the initial tissue damage, SI leads to complex cellular and molecular interactions within the central nervous system, and is characterized by the shearing of cell membranes and axons, disruption of the blood-spinal cord barrier, cell death, immune cell transmigration, and myelin degradation [2-5]. 
Neuropathic pain and inflammation greatly affect the quality of life after SI, and chronic pain is a very common and significant problem. Nonsteroidal anti-inflammatory drugs (NSAIDs) and skeletal muscle relaxants are frequently used for alleviating the pain, inflammation, and spasticity $[6,7]$. The chronic pain associated with $\mathrm{SI}$ is effectively treated with muscle relaxants like tizanidine hydrochloride $(\mathrm{TH})$.

$\mathrm{TH}$, an imidazole derivative, is an $\alpha$-2-adrenergic receptor agonist which regulates myotonolytic effects of skeletal muscle. It reduces pathologically increased painful spasticity, especially in patients with spinal cord injury. In animal studies, its mechanism of action involves depressing polysynaptic reflexes, probably by antagonizing the excitatory actions of spinal interneurons [6-8]. In addition, it is effective in reducing muscle tone in spastic patients. $\mathrm{TH}$ is an antispastic agent with similar efficacy to that of baclofen, with a more favorable tolerability profile $[9,10]$. Furthermore, the benefits of administering $\mathrm{TH}$ in a modified release formulation have been demonstrated in clinical studies, with symptoms of spasticity and disability improved by approximately $94 \%$ and $79 \%$, respectively [10]. However, TH has a short half-life $(2.5 \mathrm{~h})$, and low bioavailability (40 \%), so a frequent dosage regimen is required.

Matrix tablets prepared with suitable polymers provide an effective approach in designing SR dosage forms [11-14]. Based upon these previous studies, a SR matrix tablet formulation of $\mathrm{TH}$ could result in a reduction in the administered dose and in its frequency of intake, and result in better patient compliance.

In the present study, we formulated $\mathrm{TH}$ tablets using a wet granulation method, then characterized the SR matrix tablets using polymers [hydroxyl propyl methyl cellulose (HPMC), ethyl cellulose (EC), guar gum, and polyvinylpyrrolidone K-30 (PVP K-30)]. The resulting tablets were characterized for their in vivo motor function activity using the spinal injury rat model.

\section{EXPERIMENTAL}

\section{Materials}

$\mathrm{TH}$, hydroxypropylmethyl cellulose (HPMC K 100), EC, guar gum, PVP K-30, lactose, microcrystallin cellulose (MCC), and magnesium stearate were purchased from Sigma-Aldrich (St. Louis, MO, USA). All other chemicals were of analytical grade.

\section{Methods}

\section{Preparation of SR matrix tablets of TH}

TH matrix tablets were prepared by the wet granulation method (Table 1).

For the preparation of tablets, all the powders were passed through 80 mesh $(177 \mu \mathrm{m})$ filter. Drug and polymers (including granulating agents such as MCC and lactose) were mixed thoroughly in PVP solution (2\%), and then the resulting mass of cohesive material was passed through a $701 \mu \mathrm{m}$ size mesh. The prepared granules were dried at $45^{\circ} \mathrm{C}$ for $1 \mathrm{~h}$, then talc and magnesium stearate were added. Finally, the tablets were compressed using a tablet compression machine (single punch tablet press; TDP, Shanghai, China).

\section{Tablet properties}

Tablet thickness were determined using a Vernier caliper, in three different positions for each tablet, followed by averaging the values ( $\mathrm{n}$ $=6$ ). Tablet hardness was measured using a Monsanto hardness tester $(n=6)$.

A USP disintegration apparatus (BJ-1; Nade Lab Instrument Disintegration Testing Tablet Disintegration Tester, Zhejiang, China) was used

Table 1: Composition of SR matrix tablets of tizanidine hydrochloride (per tablet)

\begin{tabular}{lccccccccc}
\hline Formulation code & \multicolumn{10}{c}{ Ingredient $(\mathbf{m g})$} \\
& TH & HPMC K 100 & EC & $\begin{array}{l}\text { Guar } \\
\text { gum }\end{array}$ & $\begin{array}{l}\text { PVP K } \\
\text { 30 }\end{array}$ & MCC & Lactose & $\begin{array}{c}\text { Magnesium } \\
\text { stearate }\end{array}$ & Talc \\
\hline F1 & 8 & 70 & - & - & 15 & 25 & 35 & 3 & 3 \\
F2 & 8 & - & 70 & - & 15 & 25 & 35 & 3 & 3 \\
F3 & 8 & - & - & 70 & 15 & 25 & 35 & 3 & 3 \\
F4 & 8 & 35 & 35 & - & 15 & 25 & 35 & 3 & 3 \\
F5 & 8 & - & 35 & 35 & 15 & 25 & 35 & 3 & 3 \\
F6 & 8 & 35 & - & 35 & 15 & 25 & 35 & 3 & 3 \\
\hline
\end{tabular}

Note: TH: Tizanidine hydrochloride; HPMC: hydroxyl propylmethyl cellulose; PVP K30: polyvinylpyrrolidone K30; MCC micro crystalline cellulose 
to determine the disintegration time. A weight variation (WV) test was performed for 20 tablets from each batch, and the average values were calculated (Table 2). The percent weight variation was determined using equation 1 :

WV $(\%)=$ total weight of twenty tablets - sum of the individual weights of twenty tablets / total weight of twenty tablet $\times 100$

The friability test was performed using a Roche friabilator (CS2 Nade Lab Instrument Disintegration Testing Tablet Friability Tester, Zhejiang, China). Ten tablets were weighed and placed in the friabilator, rotating at $25 \mathrm{rpm}$. After 100 revolutions, the tablets were dusted and reweighed. The percentage friability was determined using equation 2 :

Friability $(\%)=[(\mathrm{Wo}-\mathrm{Wt}) / \mathrm{Wo}) \times 100]$

where Wo and Wt were the initial and final weights, respectively, before and after a hundred revolutions.

\section{Drug content}

Ten tablets of each formulation were weighed and powdered. The quantity of powder equivalent to $100 \mathrm{mg}$ of $\mathrm{TH}$ was placed in a 100 $\mathrm{mL}$ volumetric flask and made up to the volume with phosphate buffer, $\mathrm{pH}$ 6.8. The contents were agitated on a magnetic stirrer at $37{ }^{\circ} \mathrm{C}$ for $24 \mathrm{~h}$. At the end of $24 \mathrm{~h}$, the contents were analyzed spectrophotometrically at $320 \mathrm{~nm}$ after suitable dilutions (Table 2).

\section{Swelling index}

Swelling studies were performed to assess the extent of swelling for different formulations. The percent swelling was determined using equation 3:

$S(\%)=[(W s-W d) / W d] \times 100$

where Ws and Wd were the dry and swollen weights, respectively, at immersion time $t$ in the test liquid.

\section{In vitro release studies}

In vitro dissolution studies of prepared tablets were performed in triplicate in a USP XXIII 8 station dissolution test apparatus (ZRS-8L; Intelligent Dissolution Tester, Tianjin University Radio Factory, Tianjin, China) at $100 \mathrm{rpm}$ and 37 $\pm 1{ }^{\circ} \mathrm{C}$. Simulated gastric fluid $(900 \mathrm{~mL}$, without enzymes) was used as the media, and the study was performed for $12 \mathrm{~h}$. In the first $2 \mathrm{~h}, 0.1 \mathrm{~N} \mathrm{HCl}$ was used, which was changed to phosphate buffer $\mathrm{pH} 6.8$ after $2 \mathrm{~h}$. The medium was changed by vacuum filtration, and the undissolved particles were washed with $\mathrm{pH} 6.8$ phosphate buffer, then added again to the apparatus for further study. Aliquots of $5 \mathrm{~mL}$ were withdrawn at predetermined times and replaced with an equivalent amount of fresh dissolution media that was maintained at the same temperature. The withdrawn samples were filtered, diluted, and then recorded at $320 \mathrm{~nm}$ with a spectrophotometer.

\section{In vivo motor function activity of the spinal injury rat model}

Healthy male Wistar rats (200-250 g) were used for the study. The rats were kept in cages with standard environmental conditions of light and temperature. The rats were provided food and water ad libitum. Protocols of the animal studies were approved by the local Institutional Animal Care and Use Committee and performed in compliance with Directive 2010/63/EU on the handling of animals used for scientific purposes.

Rats were divided into four groups (normal control, negative control, standard, and test groups) with six rats in each group. After administration of thiopental sodium (40 mg/kg), all animals were subjected to laminectomy (except the normal control group) to produce acute spinal injury by using an extradural $40 \mathrm{~g}$ force clip compression for $10 \mathrm{~s}$ at the T7 vertebrae, until the motor nerve activity was most affected. One group of normal control animals did not undergo the laminectomy. After $10 \mathrm{~h}$, the experiment was initiated. Control groups were fed a suspension of $2 \%$ Tween 80 . The standard group received methyl prednisolone (MP) (30 $\mathrm{mg} / \mathrm{kg}$ ) intravenously at $30 \mathrm{~min}$ post injury. The test groups received an aqueous suspension of the TH SR tablets F4 and F5 per oral (p.o.) $(1,000 \mu \mathrm{g} / \mathrm{kg})$. At the end of $24 \mathrm{~h}$, the motor nerve activity was determined by observing the performance of rats in the horizontal bar test. In this test, the rats were mounted on an assembly of a horizontal bar ( $2 \mathrm{~mm}$ diameter; $40 \mathrm{~cm}$ long) mounted on two supports, $50 \mathrm{~cm}$ in height. The rat was held by the tail, and allowed to touch the middle of the bar with only its forepaws. Its tail was released, and the stopwatch was simultaneously started. The time spent by rats on the horizontal bar was recorded, and scored as $1-5$ seconds $=1 ; 6-10$ seconds $=2 ; 11-20$ seconds $=3 ; 21-30$ seconds $=4 ;>30$ seconds $=$ 5 ; and touching of the bar support with a forepaw $=5$. If 5 points were achieved, then a $4 \mathrm{~mm}$ diameter bar was used again for the same rat, with the addition of 2 in scoring for the respective timings. 


\section{Statistical analysis}

Results were expressed as mean values and standard deviations ( $\pm S D$ ), and the significance of the difference was analyzed by the Student's ttest, using Origin ${ }^{\circledR} 9$ software, LA, US. A $P$-value less than $0.05(p<0.05)$ was considered significant.

\section{RESULTS}

The prepared SR matrix tablets of $\mathrm{TH}$ were evaluated for various physicochemical parameters (Table 2).

The weight variations of all the formulations were not significant and were within the pharmacopoeia limits of $\pm 7.5 \%$. The tablets also showed hardness in the range of $3.5 \pm 0.75$ $\mathrm{kg} / \mathrm{cm}^{2}$ to $5.5 \pm 0.88 \mathrm{~kg} / \mathrm{cm}^{2}$. The percentage friability was less than $1 \%$ for all the formulations, indicating mechanical stability of the formulated tablets. Content uniformity for all formulations ranged from $94.72 \pm 0.05 \%$ to $98.80 \pm 0.03 \%$, and the contents were in compliance with pharmacopoeia limits. The highest swelling was found for formulation F6, which contained HPMC and guar gum.

The percent cumulative drug release for all the formulations were in the following order: F5 > F4 $>F 1>F 6>F 2>F 3$ (Fig 1).

Formulation F5 showed the higher drug content and highest cumulative drug release percentage. The best fit models for TH were the Higuchi models for F3 and F5, while the other models showed first-order release kinetics. The $\mathrm{n}$ values were greater than 0.6 , suggesting non-Fickian diffusion (Table 3).

Table 2: Evaluation of SR matrix tablets of tizanidine hydrochloride

\begin{tabular}{|c|c|c|c|c|c|}
\hline Code & $\begin{array}{l}\text { Weight } \\
\text { variation } \\
\text { (mg) }\end{array}$ & $\begin{array}{l}\text { Hardness } \\
\left(\mathrm{kg} / \mathrm{cm}^{2}\right)\end{array}$ & $\begin{array}{c}\text { Friability } \\
(\%)\end{array}$ & $\begin{array}{l}\text { Content } \\
\text { uniformity } \\
(\%)\end{array}$ & $\begin{array}{c}\% \\
\text { Swelling } \\
\text { (4 hours) }\end{array}$ \\
\hline F1 & $150 \pm 0.35$ & $5.0 \pm 0.59$ & $0.42 \pm 0.6$ & $95.40 \pm 0.05$ & $39.4 \pm 0.101$ \\
\hline $\mathrm{F} 2$ & $150 \pm 0.76$ & $5.5 \pm 0.88$ & $0.45 \pm 0.09$ & $98.80 \pm 0.03$ & $34.7 \pm 0.009$ \\
\hline F3 & $150 \pm 0.48$ & $3.5 \pm 0.75$ & $0.72 \pm 0.07$ & $97.71 \pm 0.02$ & $42.2 \pm 0.023$ \\
\hline $\mathrm{F} 4$ & $149 \pm 0.33$ & $5.5 \pm 0.38$ & $0.21 \pm 0.02$ & $94.72 \pm 0.05$ & $24.0 \pm 0.103$ \\
\hline F5 & $150 \pm 0.69$ & $4.5 \pm 0.75$ & $0.68 \pm 0.04$ & $89.11 \pm 0.01$ & $49.0 \pm 0.03$ \\
\hline F6 & $149 \pm 0.93$ & $4.0 \pm 0.23$ & $0.77 \pm 0.03$ & $92.24 \pm 0.20$ & $52.02 \pm 0.02$ \\
\hline
\end{tabular}

Mean \pm standard deviation; F: formulation

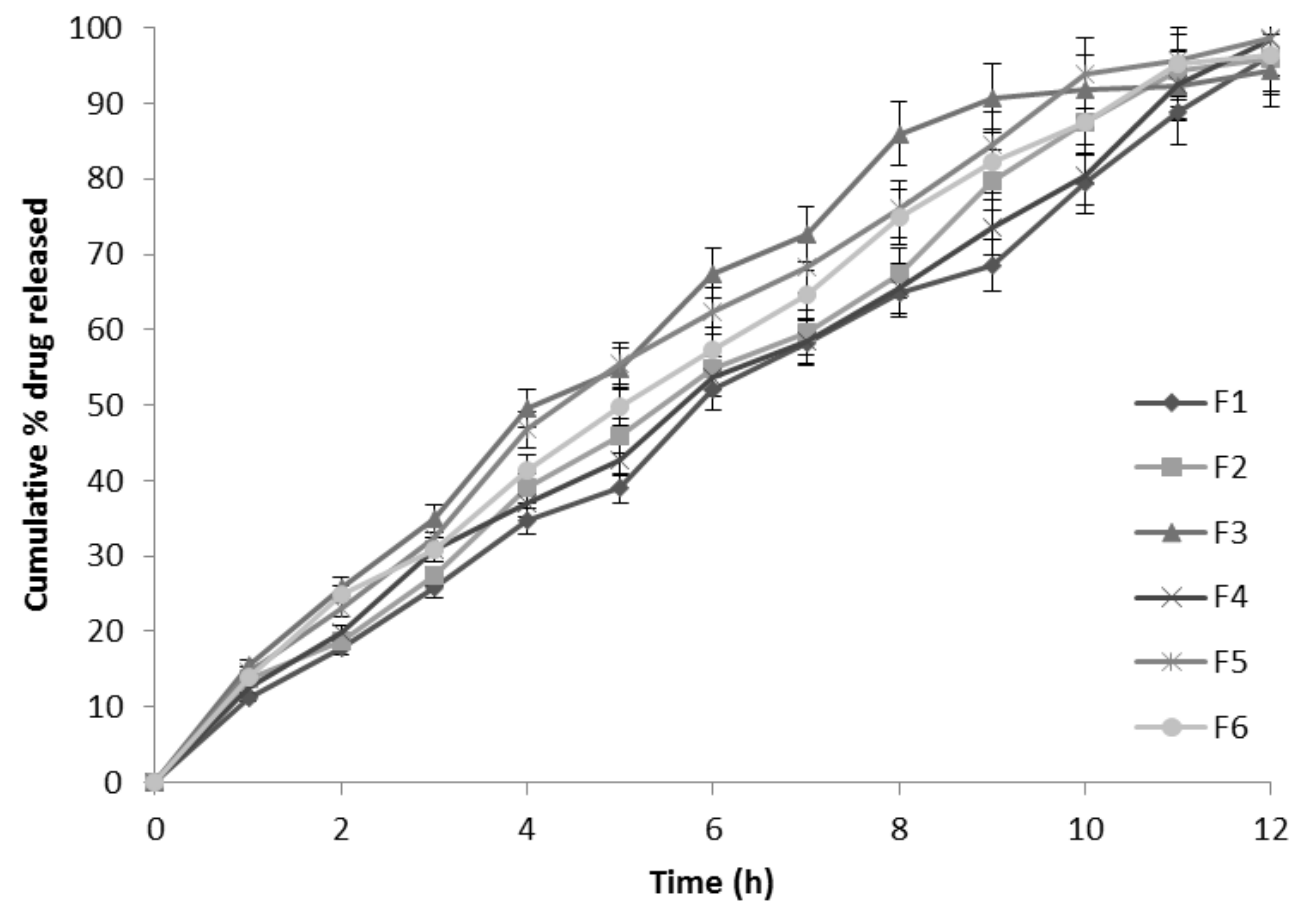

Fig. 1: In vitro drug release of SR matrix tablet formulations of tizanidine hydrochloride 
Table 3: Drug release mechanism of all the sustained-release tablet formulations of tizanidine hydrochloride

\begin{tabular}{ccccccc}
\hline Code & $\begin{array}{c}\text { Zero order } \\
\text { release }\end{array}$ & $\begin{array}{c}\text { First } \\
\text { order } \\
\text { release } \\
\mathbf{r}^{2}\end{array}$ & $\begin{array}{c}\text { Higuchi } \\
\text { release } \\
\text { kinetics } \\
\mathbf{r}^{2}\end{array}$ & $\begin{array}{c}\text { Korsmeyer-Peppas } \\
\text { release }\end{array}$ & Best fit model \\
(n value) & \\
\hline F1 & 0.565 & 0.819 & 0.796 & 0.776 & $(0.631)$ & First order \\
F2 & 0.740 & 0.921 & 0.918 & 0.825 & $(0.631)$ & First order \\
F3 & 0.786 & 0.923 & 0.940 & 0.839 & $(0.618)$ & Higuchi \\
F4 & 0.756 & 0.924 & 0.921 & 0.822 & $(0.620)$ & First order \\
F5 & 0.752 & 0.920 & 0.921 & 0.822 & $(0.620)$ & Higuchi \\
F6 & 0.772 & 0.948 & 0.930 & 0.825 & $(0.634)$ & First order \\
\hline
\end{tabular}

F: formulation; $r^{2}$ : regression coefficient

Table 4: In vivo motor function activity of SR matrix tablets of tizanidine hydrochloride in the spinal injury rat model

\begin{tabular}{lc}
\hline Group & $\begin{array}{c}\text { Total activity } \\
\text { score }\end{array}$ \\
\hline Control (normal) & $8.70 \pm 1.50$ \\
Control (negative) & $1.02 \pm 1.20$ \\
Standard (MP given i.v.) & $5.44 \pm 0.50$ \\
Test (F4) & $4.98 \pm 0.10^{\mathrm{a}}$ \\
Test (F5) & $4.60 \pm 0.24^{\mathrm{a}}$ \\
\hline${ }^{*}$ Experimental section describes the scoring system; ${ }^{a} p$ \\
$<0.05$ was considered significant; i.v. $=$ intravenous; $F$ \\
$=$ formulation; $M P=$ methyl prednisolone
\end{tabular}

On the basis of the in vitro drug release results, tablet formulation F4 (containing HPMC and EC) and F5 (containing EC and guar gum) were selected for in vivo studies to assess the effectiveness of treating motor nerve activity in the post-traumatic spinal injury rat model. The results showed that the F4 formulation showed the best recovery from spinal injury, with F4 (containing HPMC, EC, and PVP) and F5 (containing EC, guar gum, and PVP) showing activity scores of $4.98 \pm 0.10$ and $4.60 \pm 0.24$, respectively, compared to a score of $5.44 \pm 0.50$ for the standard group (Table 4).

\section{DISCUSSION}

$\mathrm{TH}$, which is an imidazoline that acts as an agonist at $\alpha$-2-adrenergic receptors, has been shown to be effective in reducing spasticity, and is an effective drug for spasticity induced by spinal injuries. Because of its swelling properties, previous studies reported that the matrix tablet showed prolonged durations of action [11-14], consistent with the observation that swelling is one of the most critical factors in sustaining drug release. In the present study, hydrophilic polymers like HPMC with guar gum (F6) showed good swelling, due to better imbibition of water or simulated gastric fluid.
Swelling increased with time, and weight gain by prepared tablets increased in direct proportion with the rate of hydration, for up to $4 \mathrm{~h}$. Later, it gradually decreased due to dissolution of the outermost tablet gel layer into the dissolution medium. In addition, the swelling was directly proportional to the polymer concentration. A matrix, upon contact with an aqueous solution, undergoes wetting, which starts from the surface, followed by the progression via microscopic pores into the inner core. The nature of the polymer therefore plays an important role in this swelling process. The presence of water in the polymer causes a stress, resulting in hydration of the polymer, which swells to yield a gelatinous viscous layer $[15,16]$.

When significant swelling occurs, the diffusional path length is increased, and drug release is retarded or sustained. The results of drug release in the present study were consistent with previous studies, which also reported that the amount of drug release was inversely proportional to the polymer concentration in prepared matrix tablets [11-12,17-22].

The use of HPMC, EC, guar gum, and PVP in the polymeric granules not only provided sustained release, but also provided complete release from the $S R$ tablets. Furthermore, the combination of HPMC and EC with PVP (F4) and EC and guar gum with PVP (F5) showed good in vitro, as well as in vivo, properties.

After treatment, the negative controls had a motor activity of only $12.75 \%$, while the F4- and F5-treated animals had motor activities of 62.25 and $57.5 \%$, respectively, compared with a motor activity of $68 \%$ for the standard group. The increased motor activity was an indication of reduced spasticity. The rat model of spinal injury demonstrated the efficacy of TH SR tablets, as compared to that of the standard. The prolonged and sustained release profile may therefore be 
suitable for patients with traumatic spinal injuries, to improve their quality of life.

\section{CONCLUSION}

Sustained release matrix tablets of $\mathrm{TH}$ prolong the time of drug release, and thus might be helpful in improving patient compliance and motor function activity in patients with posttraumatic spinal injuries. The prepared formulations showed remarkable improvement in motor function activity in the traumatic spinal injury rat model. The formulations should therefore be further tested in patients with spinal injuries, to assess their possible neuroprotective effects in reducing painful spasticity.

\section{REFERENCES}

1. Salsa $T$, Veiga $F$, Pinna ME. Oral controlled release dosage forms. I. Cellulose ether polymers in hydrophilic matrices. Drug Develop Ind Pharm 1997; 23: 929-938.

2. Liu NK, Zhang YP, Titsworth WL, Jiang $X$, Han S, Lu PH, A novel role of phospholipase $A 2$ in mediating spinal cord secondary injury. Ann Neurol. 2006; 59: 606-619.

3. Thuret S, Moon LD, Gage FH. Therapeutic interventions after spinal cord injury. Nat Rev Neurosci 2006; 7: 628643.

4. Zhang N, Yin Y, Xu SJ, Wu YP, Chen WS, Inflammation \& apoptosis in spinal cord injury. Indian $J$ Med Res 2012; 135(3): 287-296.

5. Warms CAs, Turner JA, Marshall HM, and Cardenas DD. Treatments for chronic pain associated with spinal cord injuries: many are tried, few are helpful. Clin J Pain 2002; 18: 154-163

6. Lee $S$, Zhao $X$, Hatch $M$, Chun S, Chang E., Central Neuropathic Pain in Spinal Cord Injury. Crit Rev Phys Rehabil Med 2013; 25(3-4): 159-172.

7. Chang E, Ghosh N, Yanni D, Lee S, Alexandru D, Mozaffar T., A review of spasticity treatments: pharmacological and interventional approaches. Crit Rev Phys Rehabil Med 2013; 25(1-2): 11-22.

8. Wagstaff AJ, Bryson HM. Tizanidine. A review of its pharmacology, clinical efficacy and tolerability in the management of spasticity associated with cerebral and spinal disorders. Drugs 1997; 53(3): 435-452.

9. Fuchigami T, Kakinohana O, Hefferan MP, Lukacova N, Marsala S, Platoshyn O, Sugahara K, Yaksh TL, Marsala M. Potent suppression of stretch reflex activity after systemic or spinal delivery of tizanidine in rats with spinal ischemia-induced chronic spastic paraplegia. Neuroscience 2011; 194: 160-169.

10. Kamen L, Henney HR 3rd, Runyan JD. A practical overview of tizanidine use for spasticity secondary to multiple sclerosis, stroke, and spinal cord injury. Curr Med Res Opin 2008; 24(2): 425-439.

11. Semalty A, Semalty M. Formulation and evaluation of dexamethasone matrix tablets for colon specific delivery, The Pharma Review 2006; 5: 159-162.

12. Semalty $M$, Semalty $A$, Bisht $T$. Triple layered Aceclofenac tablets of Xanthan gum and guargum: $A$ comparative study, International $J$ Pharm Sci Nanotechnol 2012; 5: 1621-1626.

13. Chien YW. Regulatory considerations in controlled release medication: Novel Drug Delivery Systems. 1st ed. New York: Marcel Dekker Publishers; 1982.

14. Efentakis M, Ronald DC, Sonel MT. Development and Evaluation of oral multiple unite and single unite hydrophilic controlled-release system. PharmSciTech 2000; 1(4): 34-38.

15. Krishnaiah YSR, Karthikeyan RS, Satyanarayana V. A three layered guar gum matrix tablet for oral controlled delivery of highly soluble metoprolol tartarate. Int $\mathrm{J}$ Pharm 2002; 241: 353-366.

16. Varshosaz J, Tavakoli N, Kheirolahi F. Use of hydrophilic natural gums in formulation of sustained-release matrix tablets of tramadol hydrochloride. AAPS PharmSciTech 2006; 7(1): E24.

17. Rezal MD, Qadir MA, Haider SS. Comparative evaluation of polymers as matrix for controlled release drug delivery. J Pharm Pharmaceutical Sci 2003; 6(2): 274291

18. Brabander CD, Vervacet $C$, Remon JP. Development and evaluation of sustained release matrix tablet. $J$ Controlled Release 2002; 77(1): 245-258.

19. Andreopopulas AG, Tarantilli PA. Xanthan gum as a carrier for controlled release of drug. J Biomaterials Appl 2001; 16: 35-38.

20. Indranil KY, Hari PS, Rana PS, Pan KT, Dinesh C, Durg $J$. Formulation, evaluation and optimization of Aceclofenac sustained release matrix tablets. Int PharmTech Res 2010; 2(1): 592-598.

21. Chavanpatil $M$, Jain $P$, Chaudhari S. Development of sustained release gastroretentive drug delivery system for ofloxacin: In vitro and in vivo evaluation. Int $\mathrm{J}$ Pharm 2005; 304: 178-184.

22. Varshosaz J, Tavakoli N. Use of hydrophilic natural gums in formulation of $S R$ matrix tablets of tramadol. AAPS PharmSci Tech 2006; 7(1): E1-E6. 